\title{
Variability of African farming systems from phenological analysis of NDVI time series
}

\author{
Anton Vrieling • Kirsten M. de Beurs • Molly E. Brown
}

Received: 6 May 2009 / Accepted: 27 January 2011 / Published online: 8 March 2011

(C) The Author(s) 2011. This article is published with open access at Springerlink.com

\begin{abstract}
Food security exists when people have access to sufficient, safe and nutritious food at all times to meet their dietary needs. The natural resource base is one of the many factors affecting food security. Its variability and decline creates problems for local food production. In this study we characterize for sub-Saharan Africa vegetation phenology and assess variability and trends of phenological indicators based on NDVI time series from 1982 to 2006. We focus on cumulated NDVI over the season (cumNDVI) which is a proxy for net primary productivity. Results are aggregated at the level of major farming systems, while determining also spatial variability within farming systems. High temporal variability of cumNDVI occurs in semiarid and subhumid regions. The results show a large area of positive cumNDVI trends between Senegal and South Sudan. These correspond to positive CRU rainfall trends found and relate to recovery after the 1980's droughts. We find significant negative cumNDVI trends near the south-coast of West Africa (Guinea coast) and in Tanzania. For each farming system, causes of change and variability are discussed based on available literature (Appendix A). Although food security comprises more than the local natural resource base, our results can perform an input for food security analysis by identifying zones of high variability or downward trends. Farming
\end{abstract}

Part of the work was done while A. Vrieling worked at the Joint Research Centre of the European Commission in Ispra (VA), Italy.

A. Vrieling $(\varangle)$

Faculty of Geo-Information Science and Earth Observation (ITC), University of Twente, P.O. Box 217, 7500 AE Enschede, The Netherlands

e-mail: a.vrieling@utwente.nl

K. M. de Beurs

Department of Geography, University of Oklahoma, 100E. Boyd Street, SEC Suite 684, Norman, OK 73019, USA

M. E. Brown

Biospheric Sciences Branch, NASA Goddard Space Flight Center, Greenbelt, MD 20771, USA 
systems are found to be a useful level of analysis. Diversity and trends found within farming system boundaries underline that farming systems are dynamic.

\section{Introduction}

Local agricultural production is a key element of food security in many African countries (Alexandratos 1999). Despite globalization and food trade, access to food remains a major problem for an important part of the population of sub-Saharan Africa (SSA). Organizations that monitor food security in Africa often use satellite remote sensing as a key indicator of variation in food production (Brown 2008). The normalized difference vegetation index (NDVI) as derived from coarse-scale satellite imagery is often used because it provides observations at a daily time step, allowing for frequent updating of the vegetation status. NDVI is defined as the difference between the near-infrared and red reflections divided by the sum of the two (Tucker 1979). Although NDVI is affected by soil background, atmospheric scattering, and is relatively insensitive to high biomass levels, it provides sufficient stability to capture seasonal and inter-annual changes in vegetation status (Huete et al. 2002). Organizations like the European Joint Research Centre (JRC), the United State's Famine Early Warning System Network (FEWS-NET), and the United Nations Food and Agriculture Organization (FAO) use NDVI time series for early warning of potential food production problems in African countries (e.g. Rojas et al. 2005).

The vigor and development of vegetation depends on available natural resources. For the African continent particularly water and nutrient availability are limiting factors. Vegetation development can be studied by looking at its phenological characteristics including germination, leaf emergence, and start of senescence. Land surface phenology is defined as the spatio-temporal development of the vegetated land surface as observed by synoptic satellite sensors (de Beurs and Henebry 2005a). At an aggregated level, NDVI time series from satellite data can approximate phenological stages and thus characterize the general vegetation behaviour within its spatial footprint (Justice et al. 1985; Reed et al. 1994). NDVI-derived measures characterizing the vegetation's temporal behavior are referred to as phenological metrics. Phenological metrics have also been used to assess food production (Funk and Budde 2009). A phenological metric of special interest is the seasonally cumulated NDVI (cumNDVI) as it is related to net primary productivity (NPP: Awaya et al. 2004; Lo Seen Chong et al. 1993).

The Advanced Very High Resolution Radiometer (AVHRR) provides the longest NDVI record with global coverage (Tucker et al. 2005). Using the AVHRR instrument on multiple satellites since 1981, the resulting 26-year vegetation data record permits the examination of variability between years as well as trends (de Beurs and Henebry 2005b). In relation to farming systems trends and variability in NDVI records can give information on the stability of the natural resource base of the system. For example, areas experiencing frequent droughts will likely show high variability in one or more phenological metrics. For Africa, AVHRR time series have been used extensively for trend analysis (e.g. Fuller 1998; Herrmann et al. 2005), but to a more limited extent in relation to phenology. An exception is Heumann et al. (2007) who found positive cumNDVI trends in 250-1100 $\mathrm{mm}$ rainfall regions of West-Africa for 1982-2005, but did not analyze areas outside the $4^{\circ}-18^{\circ} \mathrm{N}$ range. 
Tateishi and Ebata (2004) found similar positive cumNDVI trends for the 1982-2000 period.

Dixon et al. (2001) classified 72 global farming systems (GFS) in six developing regions worldwide. They define farm systems as the household, its resources, and the resource flows and interactions at the individual farm level. A farming system is defined as a group of individual farm systems that broadly contain a similar resource base, enterprise patterns, household livelihoods and constraints. The main goal of their work was to provide a framework within which agricultural development strategies may be determined. Their classification was based on the available natural resource base and the dominant pattern of farm activities and household livelihoods.

The purpose of this study is to characterize nine of the farming systems (FS) identified in sub-Saharan Africa with respect to land surface phenology as measured by the AVHRR record. Based on a consistent processing for the period 1982-2005 we determine phenological variability and trends. The main focus is on cumNDVI. We aggregate our results from $8-\mathrm{km}$ pixels to farming system polygons. Because Dixon et al. (2001) stress that sharp boundaries between neighboring farming systems do not occur, we first subdivide the polygons to encompass spatial variability within each system. Although the study deals with farming systems we choose to not specifically focus on agricultural areas only, but to evaluate the total natural resource base of each system. A consequence of that choice is that observed trends cannot merely be attributed to changes in vegetation phenology, but also to land cover conversions (Brink and Eva 2009). Hence, we show where consistent trends occur which indicate a change in the natural resource base. Potential drivers of change are identified based on literature and we compare our phenology results with rainfall and temperature trends for the same time period. We discuss possible implications for food security.

\section{Materials and methods}

\subsection{Farming systems}

The farming systems map for SSA was taken from Dixon et al. (2001). In this study we address only the agricultural FS that are predominantly rainfed, as shown in Fig. 1. Consequently, the arid, pastoral, irrigated, and urban classes were not considered. Additionally the forest based system was discarded, because limited intra-annual NDVI variability and the dominant shifting cultivation practices prevent effective phenological characterization. This leaves nine farming systems, which we order as in Dixon et al. (2001). The farming systems and their principal crops and livestock are listed below:

- Tree crop (TC): cocoa, coffee, oil palm, rubber, yams, maize;

- $\quad$ Rice-tree crop (RT): rice, banana, coffee, maize, cassava, legumes, livestock;

- Highland perennial (HP): banana, plantain, enset, coffee, cassava, sweet potato, beans, cereals, livestock, poultry;

- Highland temperature mixed (HT): wheat, barley, teff, peas, lentils, broadbeans, rape, potatoes, sheep, goats, livestock, poultry;

- Root crop (RC): yams, cassava, legumes;

- Cereal-root crop mixed (CR): maize, sorghum, millet, cassava, yams, legumes;

- Maize mixed (MM): maize, tobacco, cotton, cattle, goats, poultry; 
- Large commercial and smallholder (LC): maize, pulses, sunflower, cattle, sheep, goats;

- Agro-pastoral millet/sorghum (AP): sorghum, pearl millet, pulses, sesame, cattle, sheep, goats, poultry;

Dixon et al. (2001) provide a more detailed description of the FS and their characteristics. We use the two-letter codes above to refer to the systems.

Individual FS polygons often cover large areas. To address spatial variability within farming systems we combine the FS map with sub-national administrative layers. For this the first sub-national administrative units of FAO's GAUL (Global Administrative Unit Layers) database were used. Due to different political organization per country, the size of individual units may greatly vary. To obtain a fairly homogeneous unit size, a combination of the FS map and GAUL was performed in the following way. First, FS polygons of less than $40,000 \mathrm{~km}^{2}$ were conserved in their present form and not subdivided. Second, an intersection was performed between the remaining FS and GAUL polygons. Third, iteratively for resulting polygons smaller than $20,000 \mathrm{~km}^{2}$ the smallest polygon was merged with the smallest neighboring polygon having the same FS and preferentially falling within the same country. If no neighboring polygon of the same FS was present in the same country, polygons of different countries were merged. The final result is the same FS map but with a subdivision of large FS units (the grey lines in Fig. 1). The area threshold values were set in such a way that each polygon contained sufficient NDVI pixels for effective aggregation (see Section 2.2).

\subsection{NDVI data and phenology extraction}

We used the AVHRR NDVI dataset from the NASA Global Inventory Monitoring and Modeling Systems (GIMMS) group at the Laboratory for Terrestrial Physics

Fig. 1 Global farming systems of sub-Saharan Africa addressed in this article (after Dixon et al. 2001). The thin grey lines delimit the sub-units used in our analysis. In most cases country borders (black lines) are respected, but a sub-unit may occasionally span two countries

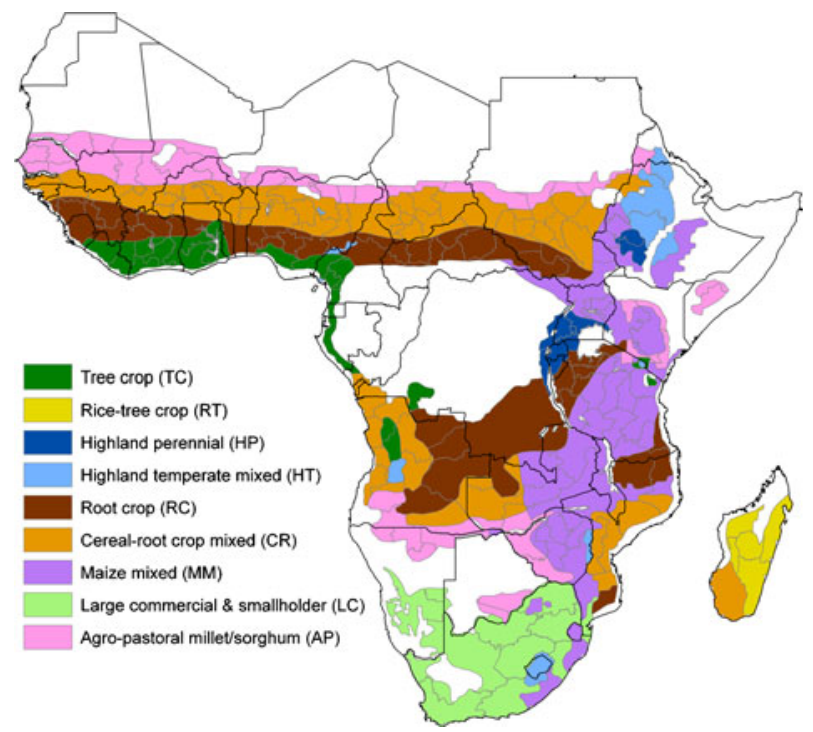


(Tucker et al. 2005). The dataset contains 15-day maximum value NDVI composites at $8-\mathrm{km}$ resolution for July 1981 to December 2006. It is based on six NOAA (National Oceanic and Atmospheric Administration) satellites. SPOT Vegetation NDVI is used for intercalibration between NOAA-14 and NOAA-16 and -17. The dataset is corrected for factors not relating to vegetation, although some data problems remain in the current version (Pinzón et al. 2005). Due to AVHRR's wide spectral bands the presence of water vapor in the atmosphere lowers NDVI values, although maximum-value compositing reduces this effect (Brown et al. 2008). To remove residual cloud contamination, we applied the iterative Savitzky-Golay algorithm (Savitzky and Golay 1964) as described by Chen et al. (2004). NDVI-values below 0 and rises of more than 0.30 NDVI units in 15 days were masked out before applying the filter. All subsequent analysis was based on the Savitzky-Golay filtered data.

Several methods exist for extracting phenology from satellite data, but field-based validation efforts are still limited (Reed et al. 2009). In North America groundmeasured plant phenology was compared with 10 extraction methods (White et al. 2009). The comparison showed that the start of the season was generally well represented by the variable threshold method of White et al. (1997) and a harmonic analysis model based on the Fourier-transformation by Roerink et al. (2000). For the West African Sahel, Brown and de Beurs (2008) compared a quadratic method with ground measured sowing dates and obtained good results. However, the quadratic method may be less robust for other environments (White et al. 2009) and bimodal seasons. We selected the variable threshold method White et al. (1997) to extract phenology from the NDVI time series. This method determines per year and per pixel the annual maximum and minimum NDVI. The average between both is taken as the threshold. Onset and offset of the season are the points where the NDVI profile passes the threshold value in upward and downward direction respectively. We call these points start of season (SOS) and end of season (EOS).

Phenology extraction for the entire SSA is somewhat complex since seasons span different calendar years and double seasons occur. To limit strong artificial phenology fluctuations between years, we extended White's method with a searching algorithm. First, a long term average NDVI-profile was constructed per pixel (i.e. the NDVI climatology). Based on this profile the occurrence of maxima and minima was documented. A maximum for a pixel is the point where it has a) the highest value in a window ranging from three values before and three values after, and b) is higher than the average value of absolute maximum and minimum for that pixel. For the minimum a similar logic was applied. Two seasons occur for a pixel if two maxima and two minima separate each other. Based on the NDVI climatology per pixel and its corresponding maxima and minima, we then extract phenology from the yearly data. For that purpose, we search per season and pixel the SOS in the range of three values before minimum and three values after corresponding maximum. This procedure is illustrated in Fig. 2. EOS is then the first moment after the yearly maximum where the profile attains the threshold value. The values of SOS and EOS are interpolated between different 15-day periods, if needed.

We discarded arid areas, dense forests, and areas with limited intra-annual vegetation variability by masking pixels that had an average NDVI outside the range $0.2-$ 0.7 or a coefficient of variation of less than 0.1 . To avoid problems of seasons spanning different calendar years, we always assessed two years at a time. This resulted 


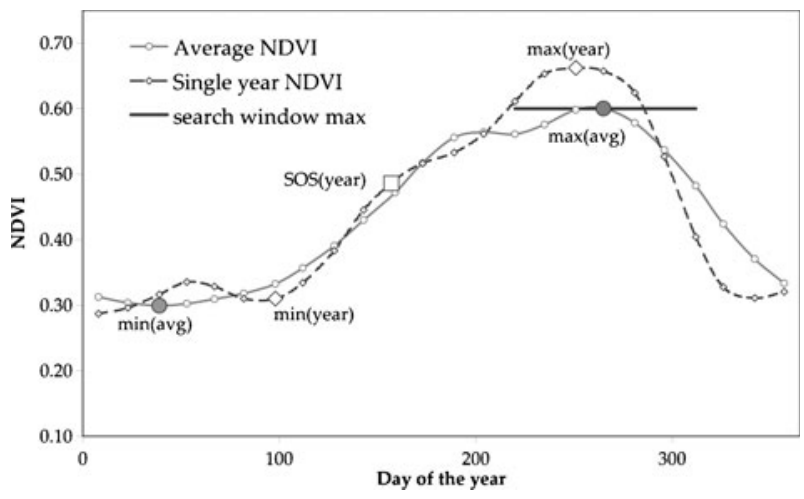

Fig. 2 Illustration of searching algorithm to extract phenology. For the NDVI climatology the maximum and minimum are determined. Then for individual years the maximum is determined within a temporal search window (three periods before and after). Subsequently we find the first preceding minimum, which should be between three periods before average minimum and the year maximum. Finally, we find SOS where the NDVI profile reaches the $50 \%$-value between yearly maximum and minimum

for each pixel in a time series of phenology metrics, ranging from 1982 to 2005 . The metrics extracted and used in further analysis are SOS, length of season (LOS), maximum NDVI value (maxNDVI), and cumulated NDVI over the season (cumNDVI). These are illustrated in Fig. 3 and are the same as in Brown et al. (2010). The extraction of the additional metrics is straightforward based on SOS, EOS, and the filtered time series. LOS is the difference between EOS and SOS. We defined that LOS should be at least more than a month to be valid, and before calculating other metrics. If present, the metrics were also calculated for the second season. For the purpose of the analysis described here, we combined the cycles for LOS, maxNDVI, cumNDVI. If two cycles are present, per pixel we take LOS as the sum of the two LOS values for cycle 1 and 2 . The same was done for cumNDVI, while for maxNDVI the maximum value of both cycles was taken.

Fig. 3 Phenology metrics addressed in this article, i.e. start of season (SOS), end of season (EOS), length of season (LOS), maximum NDVI value (maxNDVI), and cumulated NDVI over the season (cumNDVI)

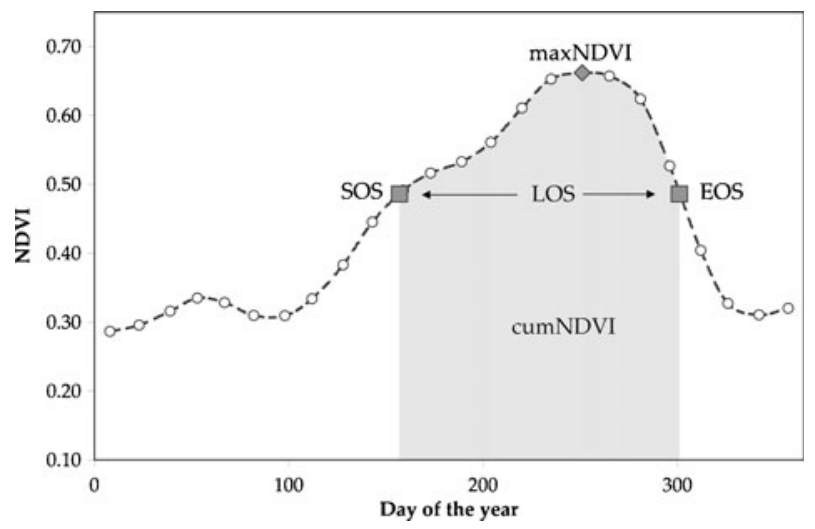


The phenology metrics were aggregated 1) per farming system divided in north and south of the equator, and 2) for the polygons defined in Section 2.1. Such aggregation could be done based on a crop mask to focus on agricultural areas only. Vrieling et al. (2008) combined AfriCover (http://www.africover.org/), FAO crop zones, and GLC2000 (Global Land Cover: Bartholomé and Belward 2005) to obtain an optimal crop mask for Africa, and aggregated phenology based on this mask. More sources for crop masks exist (e.g. Bicheron et al. 2008; Biradar et al. 2009; Friedl et al. 2002; Ramankutty et al. 2008). However, datasets show strong discrepancies between them (Fritz and See 2008) while many products contain a large number of mosaic classes (Bicheron et al. 2008). Our experience learns that for areas erroneously omitted as crops no aggregated phenology results could be obtained, or aggregated values were only based on a very limited number of pixels. Our choice for not using a crop mask in this study is based on the following reasons: 1) we choose to evaluate the total natural resource base of the farming systems (see also Section 1),2) an accurate well-validated crop mask does not exist for the region while using a mask of limited or unknown accuracy can strongly bias our results, and 3) crop distribution changes over time which is not accounted for in existing stationary crop masks. Averaging the derived metrics (i.e. pixels) inside a polygon thus gives us per year the phenology metrics for the average resource base. To obtain a valid representative value for a specific polygon and year, at least 25 pixels with valid phenology metrics should be present. A second season was only documented for SOS if the number of pixels with valid phenology metrics for the second season were at least $50 \%$ of pixels for the first season. Hence below $50 \%$ a second season was judged not representative for the polygon.

\subsection{Variability and trend calculation}

Summary statistics per farming system were derived for each phenology metric. We divided the farming systems in above the equator $(\mathrm{N})$ and below the equator $(\mathrm{S})$. SOS is not included in these statistics because of high differences that may occur for the same farming system in different areas (e.g. Agro-Pastoral in Kenya and Mali). For the other three metrics this problem does not occur. We give the aggregated multi-year average and two measures of standard deviation. The temporal standard deviation $\sigma_{t}$ refers to the dispersion of the phenology metric through time. Per pixel the standard deviation for a time series of a phenology metric is calculated and subsequently averaged for all pixels falling within the farming system. The spatial standard deviation $\sigma_{s}$ indicates the dispersion of the phenology metric in space. It is the standard deviation of the (temporal) mean phenology pixel values that fall within the farming system. High values of $\sigma_{s}$ indicate that the phenology metric is spatially heterogeneous within the farming system. High values of $\sigma_{t}$ indicate that the metric has high temporal variability.

At the more detailed polygon level (Section 2.1) we evaluated the multi-year average, the temporal variability, and the presence of a trend for each metric. Variability for SOS was assessed using temporal standard deviation $\left(\sigma_{t}\right.$ : in days). For LOS, maxNDVI, and cumNDVI we evaluated variability with the (temporal) coefficient of variation $\left(C V_{t}\right)$, which is a normalized measure dividing $\sigma_{t}$ over the mean. Possible trends were assessed with the non-parametric Spearman rank correlation with only time (year) as the explanatory variable (Spearman 1904). The Spearman correlation 
is based on rank values of the variables and consequently does not assume a linear relation. Trends were classified based on sign of the correlation (positive or negative) and significance level $(p<0.05$ and $p<0.10)$.

\subsection{Climate data}

To assess whether climate is an important driver for the NDVI-derived trends, we analyzed gridded monthly precipitation and mean temperature time series data (TS3.0) from the Climate Research Unit (CRU) of the University of East Anglia (Mitchell and Jones 2005). The $0.5^{\circ}$ cells were spatially aggregated for the same polygons of Section 2.1 by averaging. Temporal aggregation was then applied based on the multi-annual average SOS/EOS dates derived from the NDVI time series. This resulted in a single value for each year (season) and polygon. Generally a time delay occurs between the onset of rainfall and vegetation green-up. Therefore we temporally aggregate between SOS minus 30 days until EOS (i.e. SOS is shifted to 30 days earlier). Trends in the aggregated climate data were determined for 19822006 following the same procedure as described in Section 2.3.

\section{Results}

Table 1 provides summary statistics of three phenology metrics (LOS, maxNDVI, cumNDVI) by farming system. Mean values of LOS and cumNDVI of Table 1 are strongly correlated $(r=0.98)$ at this coarse aggregation level. Correlation coefficients for mean maxNDVI vs cumNDVI are 0.93 , and 0.86 for LOS vs maxNDVI. At

Table 1 Summary statistics for phenological metrics length of season (number of days), maximum NDVI, and cumulative NDVI aggregated per farming system

\begin{tabular}{|c|c|c|c|c|c|c|c|c|c|}
\hline \multirow[t]{2}{*}{ Farming system } & \multicolumn{3}{|c|}{ Length of season } & \multicolumn{3}{|c|}{ Maximum NDVI } & \multicolumn{3}{|c|}{ Cumulative NDVI } \\
\hline & Mean & $\sigma_{t}$ & $\sigma_{s}$ & Mean & $\sigma_{t}$ & $\sigma_{s}$ & Mean & $\sigma_{t}$ & $\sigma_{s}$ \\
\hline Tree crop N & 170 & 33 & 46 & 0.73 & 0.08 & 0.07 & 7.68 & 1.45 & $\overline{1.86}$ \\
\hline Tree crop S & 210 & 30 & 41 & 0.73 & 0.06 & 0.08 & 9.58 & 1.18 & 2.33 \\
\hline Rice-tree crop S & 162 & 32 & 22 & 0.67 & 0.04 & 0.09 & 6.88 & 1.12 & 1.24 \\
\hline Highland perennial $\mathrm{N}$ & 196 & 33 & 41 & 0.74 & 0.06 & 0.07 & 9.37 & 1.44 & 1.98 \\
\hline Highland perennial S & 179 & 34 & 46 & 0.71 & 0.06 & 0.07 & 8.19 & 1.40 & 2.09 \\
\hline Highland temp. $\mathrm{N}$ & 148 & 28 & 40 & 0.66 & 0.06 & 0.12 & 6.32 & 1.00 & 2.41 \\
\hline Highland temp. S & 181 & 30 & 30 & 0.64 & 0.05 & 0.09 & 7.48 & 1.02 & 1.90 \\
\hline Root crop N & 202 & 28 & 26 & 0.74 & 0.05 & 0.08 & 9.27 & 1.08 & 1.49 \\
\hline Root crop S & 219 & 28 & 21 & 0.75 & 0.04 & 0.06 & 10.28 & 1.10 & 1.38 \\
\hline Cereal-root crop N & 155 & 25 & 26 & 0.67 & 0.05 & 0.08 & 6.47 & 0.85 & 1.37 \\
\hline Cereal-root crop S & 205 & 29 & 28 & 0.71 & 0.05 & 0.09 & 9.21 & 1.11 & 1.96 \\
\hline Maize mixed $\mathrm{N}$ & 185 & 30 & 44 & 0.70 & 0.06 & 0.11 & 8.34 & 1.22 & 2.84 \\
\hline Maize mixed S & 187 & 30 & 30 & 0.70 & 0.05 & 0.08 & 8.32 & 1.15 & 1.85 \\
\hline Large comm. S & 138 & 31 & 31 & 0.53 & 0.07 & 0.14 & 4.87 & 1.00 & 2.05 \\
\hline Agro-pastoral N & 111 & 22 & 19 & 0.51 & 0.07 & 0.10 & 3.56 & 0.67 & 0.95 \\
\hline Agro-pastoral S & 162 & 31 & 31 & 0.59 & 0.06 & 0.11 & 6.11 & 1.08 & 1.87 \\
\hline
\end{tabular}

$\mathrm{N}$ includes all pixels above the equator, while $\mathrm{S}$ all pixels below. Temporal standard deviation $\sigma_{t}$ is the mean $\sigma$ 's of all pixels in a farming system, with each pixel's $\sigma$ is calculated for the 25-year period. Spatial standard deviation $\sigma_{s}$ is the $\sigma$ of all pixel means within a farming system 
the sub-FS aggregation level described in Section 2.1 (sub-units of Fig. 1) these correlations get slightly lower ( $r=0.94,0.91,0.74$ respectively). Most variables contained in Table 1 have positive correlations (although in some cases not significant), except for the $\sigma_{t}$ and $\sigma_{s}$ of maxNDVI. The strongest negative correlation $(r=-0.73)$ is between mean (maxNDVI) and $\sigma_{s}$ (maxNDVI). This indicates that more arid farming systems (lower maxNDVI) have higher spatial variability of (maximum) vegetation cover.

The farming systems of the semiarid zones (Large Commercial, Agro-Pastoral) show the lowest mean values of LOS, maxNDVI, and cumNDVI. Table 1 displays important differences between the same farming systems found above and below the equator for mean LOS (and consequently cumNDVI). For most farming systems that occur in western Africa, mean LOS and cumNDVI are lower in the northern hemisphere than the same systems in the southern hemisphere. Mean maxNDVI is more consistent between north and south. Maize Mixed is very similar in both hemispheres, except for the higher $\sigma_{s}$ values in the north. This higher spatial variability is probably due to the stronger importance of bimodal rainfall patterns found in Maize Mixed areas above the equator, making the aggregation a mixture of single and double season values.

Figure 4 displays the mean SOS, $\sigma_{t}$ of SOS, and the SOS Spearman trend. Polygons for which a second season was identified (Section 2.2), are shown on the lower part. On average for the polygons displayed, $87 \%$ of the pixels inside the polygon area contained valid phenology metrics. Here, $\sigma_{s}$ is omitted because we now represent spatial variability by using smaller units. A smooth gradient of mean SOS can be discerned from the line Senegal-Central Sudan southwards. Here, SOS for the AgroPastoral farming system is around July, for the Cereal-Root crop system around June, and in April-May for the Root and Tree Crop systems. For East Africa (Ethiopia, Kenya, Uganda, Somalia) polygons with a significant separable second season are found. These correspond to areas in Maize Mixed, Agro-Pastoral, Highland Perennial and Highland Temperate systems. The areas with two seasons towards the west correspond to the Tree Crop farming system. In Southern Africa, SOS is generally between October and January, except for the Western Cape and part of

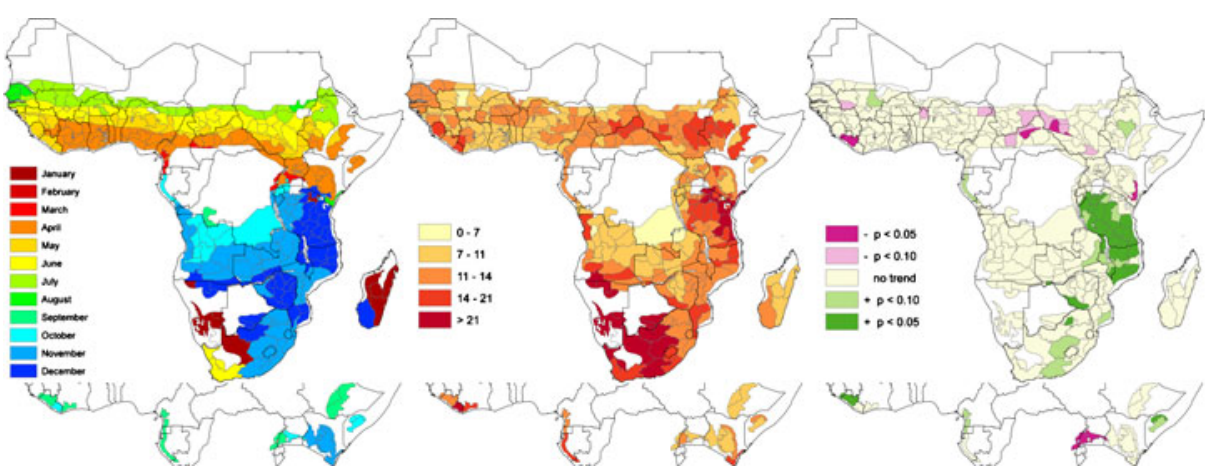

Fig. 4 Mean start of season (left), $\sigma_{t}$ of SOS (middle; in days), and Spearman trend of SOS (right) based on AVHRR NDVI time series. The lower part shows the values for the second season for places where a second season occurs 
Northern Cape provinces of South Africa, having a Mediterranean climate (Cs) and SOS is in June.

Temporal variability of the aggregated SOS values $\left(\sigma_{t}\right)$ ranges from less than a week to more than three weeks. Large Commercial and Agro-Pastoral in Southern Africa and Maize Mixed in Tanzania are the most variable systems.

Several regions show significant trends of SOS for the 1982-2005 period. The most striking are the positive trends in Tanzania, Malawi, and northern Mozambique, corresponding to Maize Mixed, Root Crop, and Cereal-Root crop farming systems. The positive trend means SOS is gradually delayed. When applying linear regression, slope parameters in this area are around $1.0(p<0.05)$, implying that in 25 years SOS is delayed by 25 days.

The mean, $C V_{t}$, and Spearman trend of the combined seasons of cumNDVI are presented in Fig. 5. The mean cumNDVI is simply the addition of 15-day NDVI values during the season plus interpolated values if SOS or EOS falls between two 15day periods. For Agro-Pastoral and Large Commercial systems, the mean cumNDVI values are low, similar to the results presented in Table 1 . Nonetheless, the mean of Fig. 5 also displays strong spatial variability within farming systems. For example, the high $\sigma_{s}$ value for cumNDVI of the Maize Mixed system from Table 1 translates into a high range of mean cumNDVI values in Fig. 5, i.e. from less than 6.0 in Kenya (two seasons) to more than 10.0 in northern Uganda, western Ethiopia, and southern Tanzania. The line Senegal-Central Sudan southwards shows a smooth gradient of increasing cumNDVI values, while particularly Eastern Africa shows more complex mean cumNDVI patterns.

An inverse relationship can be observed between mean cumNDVI and the $C V_{t}$ for 1982-2005. Drier areas with low cumNDVI generally show a higher $C V_{t}$, which implies a higher temporal variability in semiarid farming systems (i.e. Agro-Pastoral, Large Commercial). Of course this is partly because $C V_{t}$ is $\sigma_{t}$ normalized by the mean, thus lower means increase $C V_{t}$. However, a combination of relatively low means and low $C V_{t}$ also occurs (e.g. parts of Ethiopia and South Africa). Low to moderate $C V_{t}$ values are found for Rice-Tree, Highland Perennial, Highland Temperate, Root Crop, and Cereal-Root crop systems.

The cumNDVI Spearman trend map (Fig. 5c) displays a clear grouping of significant positive and negative trends. Between Senegal and Ethiopia a large area of positive trends is found. This area corresponds to Agro-Pastoral, Cereal-Root, and

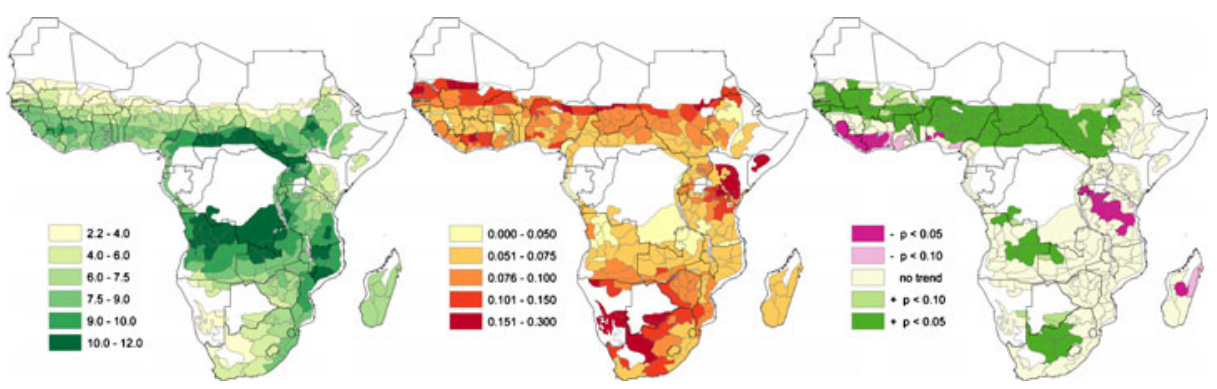

Fig. 5 Mean cumulative NDVI (left), temporal coefficient of variation $\left(C V_{t}\right)$ of cumNDVI (middle), and Spearman trend of cumNDVI (right) based on AVHRR NDVI time series. The total cumNDVI is displayed summing the seasons in case two seasons occur 
Root Crop farming systems with some inclusion of Maize Mixed in southern Sudan and Ethiopia. Results for LOS and maxNDVI indicate that the positive trend relates to a positive maxNDVI trend for Agro-Pastoral, and more frequently a positive LOS trend for Cereal-Root and Root Crop. We also find significant positive cumNDVI trends in several locations of southern Africa, comprising different farming systems. Significant negative trends occur in the south-coast of West Africa (Tree Crop and minor Root Crop), Tanzania (Maize Mixed and Root Crop), Rwanda (Highland Perennial), and Madagascar (Rice-Tree).

Figure 6 shows the trends of precipitation and temperature for the 1982-2006 period. Large areas with positive (wetting) precipitation trends can be observed. These are caused by the drought experienced in the 1980's (Nicholson 1993), i.e. the start of the time series studied. The highest concentration is found in the zone between Senegal and Ethiopia. A drying trend can only be observed for small parts of Tanzania and South Africa. For temperature, a warming trend is dominant. This positive trend is found in East and Central Africa, Madagascar, and in West Africa between Ivory Coast and Senegal. The most striking cooling trend is located in Benin, Togo, and southwest Nigeria. There is no uniform relationship between temperature and cumNDVI trends across Africa. A substantial part of the areas with a negative cumNDVI trend, also show a warming trend (parts of Tanzania, Madagascar, and between Sierra Leone and Ivory Coast). This could indicate reduced water availability due to higher evaporation losses caused by higher temperatures. Alternatively, warming could be induced by vegetation removal resulting in warmer land surfaces (Bounoua et al. 2002). For other zones the warming trend does not have a negative effect on cumNDVI. For several areas warming and positive cumNDVI trends occur simultaneously. Partly these areas also have wetting trends (Central African Republic, south Chad, east Sudan, Senegal, west Guinea), but in other cases not (e.g. east Angola, south Sudan).

The relationship of cumNDVI trends with LOS and maxNDVI trends $(p<0.10)$ is shown in Fig. 7a. For most polygons positive cumNDVI trends are supported by a

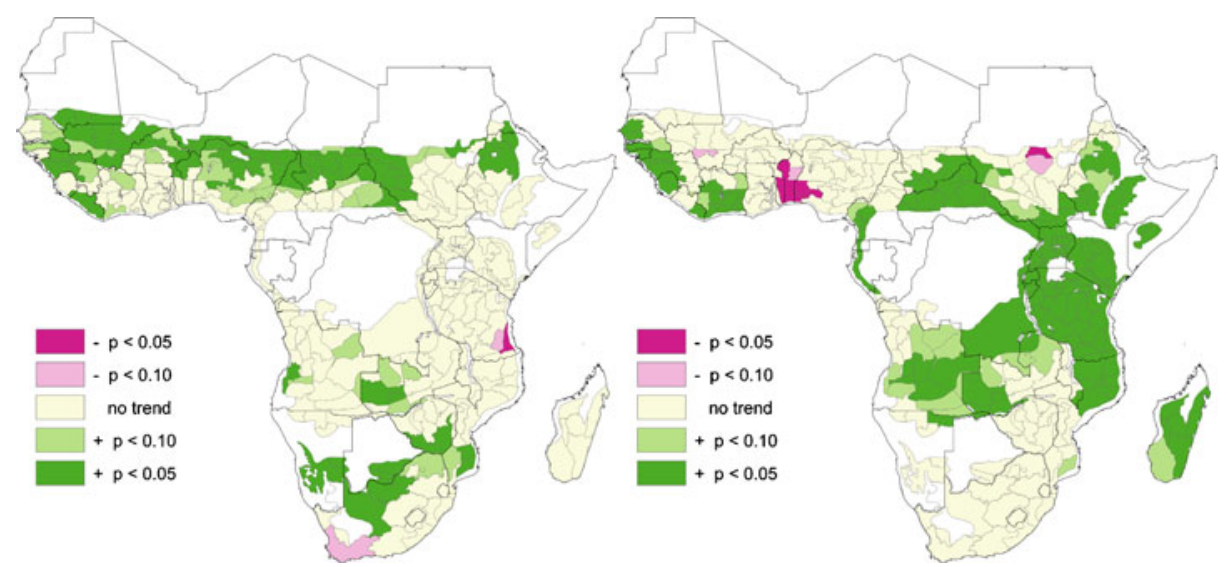

Fig. 6 Spearman trend of aggregated values of precipitation (left) and average temperature (right) based on CRU TS3.0 data for 1982-2006. Green colors indicate wetting or warming trends, while purple colors indicate drying or cooling trends 


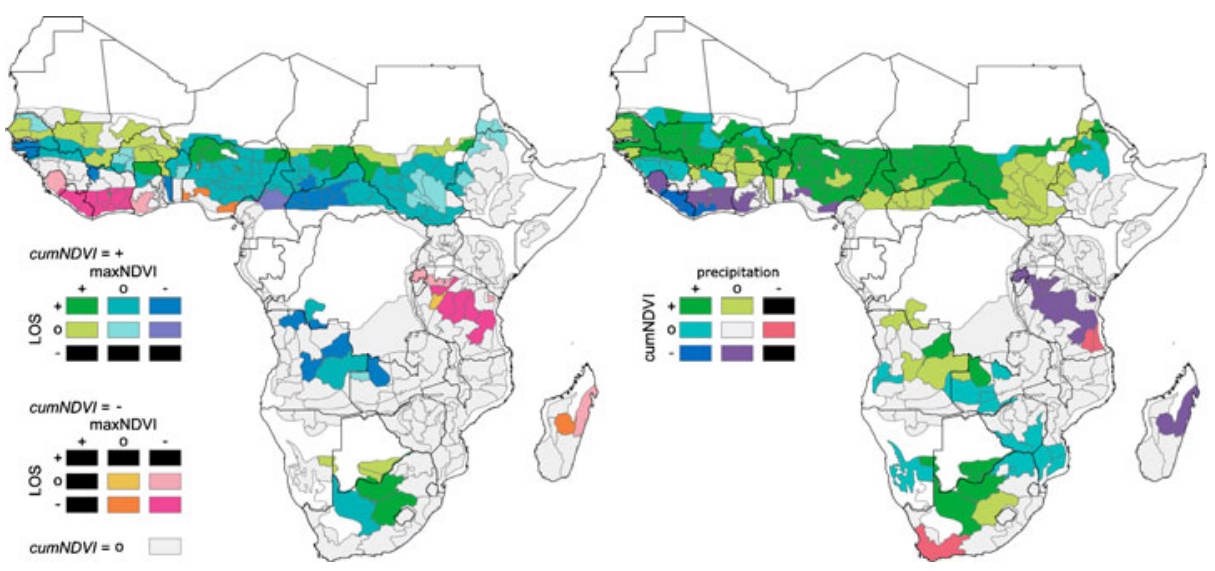

Fig. 7 Multi-variate maps (based on Teuling et al. 2010) showing the relation of cumNDVI trends with trends of other variables. The left shows whether LOS and maxNDVI trends occur for polygons having cumNDVI trends. Positive trends are shown as + , negative trends as - , and no trend as 0 . For ease of interpretation, LOS and maxNDVI trends are not shown if no cumNDVI trend is present. Black boxes in the legend mean that the combination is not present in the data. The right figure shows how cumNDVI trends relate to CRU precipitation trends. All depicted trends are significant at $p<0.10$

positive trend in either LOS or maxNDVI. Positive cumNDVI trends never correspond with negative LOS trends but do not exlude the possibility of negative maxNDVI trends (e.g. Root Crop systems in Angola, Cameroon, Central African Republic). A good part of the Agro-Pastoral systems in the Sahel show positive maxNDVI trends without LOS trends. For the Cereal-Root crop system and partly the Root crop system north of the equator many polygons have positive LOS trends. At several locations positive cumNDVI trends occur while no significant trends in either LOS or maxNDVI (e.g. in parts of Burkina Faso, Eritrea, Ethiopia, and Sudan). Negative cumNDVI trends never coincide with positive maxNDVI or LOS trends. Large parts of Tanzania (mostly Maize Mixed) and Tree Crop systems in Liberia and Ivory Coast show negative trends for all three metrics.

Figure $7 \mathrm{~b}$ displays the combined trends for cumNDVI and precipitation $(p<$ 0.10). A large part of the positive cumNDVI trends between Senegal and Ethiopia can be explained by a wetting trend in the CRU precipitation data. However, in places such as south-east Sudan a wetting trend is absent, while cumNDVI increases. Polygons with decreasing cumNDVI generally do not show precipitation trends. The only exception is a part of the Tree Crop system (Liberia, Ivory Coast) that shows decreasing cumNDVI with increasing precipitation. The few polygons with drying trends do not show trends in cumNDVI.

\section{Discussion}

The results of this study show that the farming systems of SSA may be characterized by their phenological characteristics, although often substantial spatial variability exists within the systems. This stresses the point of Dixon et al. (2001) that no 
sharp system boundaries exist. Results for average SOS (Fig. 4a) generally seem realistic. The SOS pattern and values for West Africa compare well with the NDVI analysis of Brown and de Beurs (2008). For Ghana and Burkina Faso our SOS values are within one month after rainfall-based SOS analysis (Laux et al. 2008), which can be explained by the delay between rainfall onset and vegetation green-up. For Kenya the SOS in April corresponds with the start of the long rains maize cycle as used in JRC (Rojas 2009). Zimbabwe shows again about a month delay between rainfall-based SOS (Funk and Budde 2009) and vegetation green-up. The most likely explanation for the SOS variability found in Tanzania is the large inter-annual fluctuations of the short rains (October-December) that relate to ocean circulation anomalies (Camberlin et al. 2009; Kabanda and Jury 1999). The dry period between the short and long (March-May) rains is not strong enough to clearly separate two seasons with NDVI time series, but reduced rainfall in the short rains causes a significant delay in the season onset. For South Africa, Tadross et al. (2005) show a similar pattern and high variability of season onset based on gridded rainfall data which they explain by the El Niño Southern Oscillation (ENSO). Also Reason et al. (2006) report a relationship between rainfall onset and ENSO for southern Africa.

The spatial map of mean cumNDVI (Fig. 5a) agrees with maps of net primary production (NPP) derived from satellite and additional data (Awaya et al. 2004; Goetz et al. 2000; Running et al. 2004). CumNDVI is used here as a proxy for NPP and is strongly related to abundance of natural resources. Strong differences exist in the amount of NPP that is used for human consumption (Imhoff et al. 2004). In most of SSA, the main source of food is derived from local NPP. Especially in farming systems where the ratio of population to local NPP is high, food insecurity tends to prevail (Liu et al. 2008). This is true for example in densely populated Highland farming systems and for the low NPP Agro-Pastoral system.

Vulnerability to food insecurity tends to increase when local NPP shows high temporal variability (Milesi et al. 2005). In our study, cumNDVI variability was particularly strong in the Sahelian zone, East Africa (especially Kenya and Somalia), and Southern Africa (Botswana, Namibia, South Africa, Zimbabwe). However, food security is not simply a function of local NPP, but also factors such as poverty, market forces, conflict, and HIV/AIDS play an important role (Gregory et al. 2005; Misselhorn 2005). Notwithstanding, analysis of climate and cumNDVI variability provides an important input for food security analysis. Farmers have different ways to cope with variability of available natural resources (Cooper et al. 2008; Maxwell 1996). When conditions such as drought attain unprecedented levels due to e.g. climate change, existing coping strategies may not be adequate (Battisti and Naylor 2009; Glantz et al. 2009). Therefore studying variability and trends is important. Current operational food security monitoring by organizations as FEWS-NET, JRC, and FAO concentrates on mapping of NDVI anomalies deviating from a long-term mean. However, anomalies compared to a mean do not take into account variability (possibly coupled with good coping strategies) and the occurrence of persistent trends in local NPP. Our study shows that such temporal variation in local NPP can be significant. Anomaly-based food security monitoring could thus improve when putting anomalies in perspective of normal variability and the presence of trends.

The most striking cumNDVI trend is a positive one stretching from Senegal to western Ethiopia. This trend is likely a result of recovery of droughts in the 1980's (Dai et al. 2004; Hickler et al. 2005). For most of this area, drought recovery is also 
apparent from the wetting trend we observed based on the CRU climate products (Fig. 7b). This trend is related to variability of Atlantic sea surface temperatures which suggests oceanic forcing on monsoon rains (Brown et al. 2010; Giannini et al. 2003; Philippon et al. 2007), although additional human factors are suggested (Herrmann et al. 2005). Our results based on cumNDVI show positive trends to extend further south as compared to what has been presented in other NDVI trend studies that focused on the Sahel alone (Anyamba and Tucker 2005; Herrmann et al. 2005; Olsson et al. 2005). Herrmann et al. (2005) performed a linear fitting directly on the NDVI time series for 1982-2003. Anyamba and Tucker (2005) first performed a seasonal integration for the fixed July-October period. Based on our SOS analysis this period is not a valid generalization for regions more towards the south. The analysis of Olsson et al. (2005) uses seasonal integration, but is based on the AVHRR Pathfinder dataset for 1982-1999. The extent of positive cumNDVI trends corresponds well to the pixel-based phenology study of Heumann et al. (2007) for that part of Africa. Although they apply a different phenology extraction algorithm, they also use seasonally integrated NDVI for 1982-2005 based on SOS/EOS analysis. This correspondence suggests that the trend results are not greatly influenced by the specific phenology extraction method chosen. The positive trend supports an overall global trend of increasing NPP (Cao et al. 2004; Nemani et al. 2003), which however is not apparent in most other parts of Africa based on our results. Negative cumNDVI trends on the south-coast of West Africa correspond to the negative NPP trends found by Nemani et al. (2003). However, they do not find the negative trend observed in Tanzania, which could be due to the shorter time series used (1982-1999).

Trends in phenological metrics suggest that boundaries and characteristics of farming systems may change over time due to a variable natural resource base (e.g. Fermont et al. 2008). Climate change is an important driver for such changes (Brown and Funk 2008; Lobell et al. 2008), which has an impact on land surface phenology (Brown et al. 2010; Zhang et al. 2005). Our analysis of CRU climate data shows that trends in cumNDVI are related to precipitation and temperature trends, but that these relationships are not uniform across Africa. Sub-Saharan African agriculture is highly sensitive to climatic changes (Barrios et al. 2008; Ringler et al. 2010). Consequently, it is expected to be hard hit following climate change scenarios (IPCC 2007; Kurukulasuriya et al. 2006; Parry et al. 2005). However, impacts can be highly variable through space and time (Liu et al. 2008) and call upon local adaptation strategies (Thornton et al. 2009).

Since we opted not to apply a crop mask our phenology signal results from a mixture of vegetation types within the FS polygons. Nonetheless, our study does pinpoint areas of great interannual variability and where consistent changes occur in the resource base of the farming systems. These may be caused purely by vegetation (including crop) phenological changes, but also by other factors. Human-driven land cover change, particularly cropland expansion, is among the factors explaining phenological trends (Brink and Eva 2009). Land degradation in the form of soil erosion or fertility decline may be an additional factor (Lal 2007). Dixon et al. (2001) identified various general trends for sub-Saharan Africa that affect agriculture. These include population growth, HIV/AIDS increase, diminishing tsetse infestation, increased cereal imports, and reduced government spending on extension and agricultural training. The mentioned trends and changes affect natural resources 
and may thus be reflected by trends in phenology metrics. Change attribution is an important but difficult part of land cover and land use change analysis. In Appendix A we explore potential drivers of change for the selected farming systems based on our climate analysis and published literature.

\section{Conclusion}

We determined average SOS, LOS, maxNDVI and cumNDVI, and their variability and trends for nine farming systems of sub-Saharan Africa using AVHRR NDVI time series between 1982 and 2005. Phenological characterization of the systems was possible, although substantial spatial variation is present within systems. Seasonally cumulated NDVI (cumNDVI) was the principal phenological metric in this paper as it relates to net primary productivity. Temporal variation of cumNDVI is highest in semiarid and subhumid farming systems, which implies important year to year variation of available natural resources. Climate is an important driver for this variation, as well as for trends. Positive cumNDVI trends are found in a large region stretching from Senegal to South Sudan covering different farming systems. Drought recovery since the 1980 's seems to be the strongest factor, which is supported by a wetting trend obtained from the CRU data. Regions of negative cumNDVI trends are concentrated on the south-coast of West Africa and in Tanzania. Drivers include increased population pressure, decline of fertilizer use, land degradation, and mining activities.

We discussed causes of change and variability based on available literature. Although food security comprises more than the local natural resource base, our results can provide an input for food security analysis by identifying zones of high variability or downward trends. However, results presented here should be seen as a starting point for more detailed fine-scale analysis. In view of current climate scenarios predicting a large impact on African agriculture, continued monitoring and time series analysis of phenology metrics seems indispensable. Coarse-scale analysis based on high-frequency temporal information permits identifying large-scale changes and areas/farming systems of particular concern for food insecurity. The diversity and trends within farming system boundaries suggest that farming systems are dynamic.

Acknowledgements The AVHRR data were provided by J.E. Pinzón and M.E. Brown (2007), Global Inventory Modeling and Mapping Studies, Global Land Cover Facility, University of Maryland, College Park, Maryland. The authors would like to thank Mauro Michielon for his assistance in processing the GFS and GAUL vector data. We thank Oscar Rojas and four anonymous reviewers for their helpful comments on the manuscript.

Open Access This article is distributed under the terms of the Creative Commons Attribution Noncommercial License which permits any noncommercial use, distribution, and reproduction in any medium, provided the original author(s) and source are credited.

\section{Appendix A: Discussion of results per farming system}

This appendix provides a short overview of the farming systems studied. Per system, main characteristics are described and the results of the phenological analysis of 
this study are summarized. We explore potential drivers of change for the selected farming systems based on our climate analysis and published literature. This exploration is not exhaustive, but intended as a potential starting point for other researchers to conduct studies in their local areas of expertise and regions of study to expand upon our results.

\section{A.1 Tree crop (TC)}

The TC farming system combines industrial tree crops with inter-planted food crops, grown for subsistence. Crop failure is not common within TC (Dixon et al. 2001). The negative cumNDVI trend that we find in TC of West Africa could be a result of the increased population pressure on natural resources (Brink and Eva 2009), the neglect of some industrial tree crops following decreasing profitability (Dixon et al. 2001), and deteriorating community controls on common lands (Ahuja 1998). While many TC regions are rather stable, within Ivory Coast greater variability is apparent. Although the negative trend here is significant, the higher $C V_{t}$ may partially be caused by remaining cloud effects in the GIMMS dataset. In Ivory Coast and Liberia negative cumNDVI trends co-occur with negative trends in LOS and maxNDVI. CRU data show a wetting trend for Liberia, but more commonly a warming trend (Sierra Leone, Ivory Coast, Cameroon southwards). Land cover conversions in this farming system could well be a partial cause of this trend (Bounoua et al. 2002).

\section{A.2 Rice-tree crop (RT)}

The RT system is solely found in humid areas of Madagascar. Agricultural potential is high, but small farm sizes, lack of suitable technologies, and poor markets cause poverty to prevail (Dixon et al. 2001; Minten and Barrett 2008). CumNDVI results show a spatially homogeneous system with little temporal variability. In Antananarivo and Toamasina provinces (center and east Madagascar) negative trends are found, likely caused by deforestation and agricultural expansion (Harper et al. 2007; McConnell et al. 2004). In addition, the CRU data show a significant warming trend for the entire system which may indicate a decline of water availability through higher evaporation losses. No precipitation trends are found.

\section{A.3 Highland perennial (HP)}

This system is situated in subhumid and humid highland zones of the East African Highlands. Of all SSA farming systems, it has the highest population density with consequently very small land holdings and high levels of poverty (Dixon et al. 2001). CumNDVI is relatively high and stable, although East-Congo, Rwanda, and Burundi show somewhat lower levels. Significant negative cumNDVI trends are only found in Rwanda, which match with a negative maxNDVI trend (Fig. 7a). A possible explanation is the reported widespread ongoing land degradation (Lewis and Nyamulinda 1996; Rutunga et al. 2007), which constituted the basis for the war in the 90's (Gasana 2002). The HP system has experienced significant warming since 1982 based on CRU data. However, a clear impact of this warming on phenology cannot be discerned. 
A.4 Highland temperate mixed (HT)

The HT farming system has the second highest population density and is chiefly found in the Ethiopian highlands. Problems include soil erosion, fertility decline, and lack of inputs. Weather-related crop failures are common (Dixon et al. 2001). Our results show varying levels of cumNDVI depending on location, but generally little temporal variation and trends. This agrees with the reported absence of rainfall trends over HT in Ethiopia (Cheung et al. 2008). However, the CRU analysis shows for most of Ethiopia under HT a wetting and warming trend. The problems, crop failures and climate trends described here do not imply a great reduction of overall vegetation activity as observed from our AVHRR analysis. It is however possible that finer-scale vegetation trends occur in the very heterogeneous environment of Ethiopia. These may also be positive trends, for example due to reforestation (Bewket 2002).

\section{A.5 Root crop (RC)}

The RC system is found in humid areas. It has a limited risk to crop failure and low poverty levels (Dixon et al. 2001). LOS, maxNDVI, and cumNDVI are among the highest of all farming systems with slightly lower levels of maxNDVI and cumNDVI in the West African portion. CumNDVI variability is relatively low. A big fraction of the system experiences positive cumNDVI trends (Ghana to South Sudan, plus Angola and southern Congo). These correspond to positive LOS trends (Fig. 7a), which are also found by Heumann et al. (2007). Part of this area also shows positive rainfall trends. Negative cumNDVI trends in Sierra Leone may be explained by mining activities and consequent land use changes (Akiwumi and Butler 2008), while those in Tanzania are discussed in Section A.7.

\section{A.6 Cereal-root crop mixed (CR)}

This farming system is situated in dry subhumid regions. It is marked as having excellent prospects for agricultural growth due to abundant agricultural land and low population densities, which makes the natural resource base underutilized (Dixon et al. 2001). CumNDVI above the equator has significantly lower values than below, due to a shorter LOS. Variability of cumNDVI is low to average, while the northern part is fully included in the large region of positive cumNDVI trends. These are supported both by positive maxNDVI and LOS trends and correspond to the recovery of drought in the 1980's (Dai et al. 2004; Heumann et al. 2007), which also shows in our CRU rainfall analysis. South of the equator only Bié and Uíge provinces of Angola and a part of north-western Zambia show positive cumNDVI trends, supported by a positive LOS trend.

\section{A.7 Maize mixed (MM)}

The MM system is located in dry to moist subhumid regions. Although agricultural prospects are judged to be good, the system is in crisis due to a sharp fall of input use and high fertilizer prices (Dixon et al. 2001). Varying mean cumNDVI levels indicate that high spatial variability is present within this system. Temporal variability $\left(C V_{t}\right)$ 
for MM has a strong negative relation with mean cumNDVI levels $(r=-0.69)$, which implies higher vulnerability to food insecurity in low cumNDVI areas, such as Kenya. National maize production figures for Kenya support this high variability (Rojas 2007). Western Ethiopia MM areas fall in the large band of positive cumNDVI trends. A large region of negative trends occurs in central Tanzania, which is supported by negative trends of LOS and maxNDVI. These negative trends also occur in the RC system (Section A.5). One causing factor is likely to be the strong decline in fertilizer use since 1990 due to market liberalization and consequent price increases (Malley et al. 2009; Skarstein 2005). Based on our own analysis of national FAOSTAT fertilizer consumption data, most other MM countries show positive trends in this time period, although more recent declines occur (e.g. Zimbabwe). Nonetheless, positive trends in fertilizer consumption may be compensated for by increasing crop areas, hence still lowering the fertilizer use per hectare. A second factor for declining cumNDVI is a reported rainfall decrease and the increase of dry spells (Enfors and Gordon 2007; Giannini et al. 2008; Schreck III and Semazzi 2004; Slegers 2008). Our CRU analysis does not show a decrease in rainfall for 19822006, although a significant warming trend is observed, which may imply higher evaporation losses and hence drier conditions. Other potential drivers are rapid population growth and soil fertility decline (Enfors and Gordon 2007; Malley et al. 2009) causing an increased pressure on available natural resources. These processes result in declining maize surpluses thus threatening national food security (Dixon et al. 2001).

\section{A.8 Large commercial \& smallholder (LC)}

The LC farming system comprises scattered smallholder and large-scale commercial farming in semiarid and dry subhumid zones of South Africa and Namibia. Poverty among smallholders is severe due to poor soils and frequent droughts (Dilley 2000; Dixon et al. 2001). Mean cumNDVI is generally low, while temporal variability varies from low in Eastern Cape and western provinces of South Africa (SA) to high in the drier Northern Cape province (SA) and Namibia. CumNDVI is strongly linked to annual rainfall (Helldén and Tottrup 2008; Wessels et al. 2007). Significant positive trends of cumNDVI are found in Northern Cape, North West, and Free State provinces (SA), which for the first two mentioned provinces are supported by positive CRU rainfall trends. In semiarid systems, SOS variability is an important characteristic affecting crop production (Brown and de Beurs 2008; Tadross et al. 2005). SOS temporal variability of Fig. 4 corresponds well with the SOS variability map by Tadross et al. (2005) derived from a product based on rain gauge data only, with lower values occuring in eastern SA.

\section{A.9 Agro-pastoral millet/sorghum (AP)}

Crop production and livestock are of similar importance in the AP farming system. It is situated in semiarid zones and pressure on available natural resources is high. Crop failures are mostly attributed to droughts and poverty is extensive (Dixon et al. 2001). Together with the LC system, mean cumNDVI values are among the lowest (Table 1) and closely linked to rainfall and soil moisture availability (Nicholson et al. 1990). Furthermore, the cumNDVI temporal variation is generally very high (Fig. 5) 
due to high rainfall variability, thus impacting food security (Ifejika Speranza et al. 2008; Mishra et al. 2008). Farmers adapt their land management to this variability. Yields can be improved through the use of soil and water conservation measures which also increase soil fertility (Graef and Haigis 2001; Smaling and Dixon 2006), although agricultural growth potential is modest (Dixon et al. 2001). The Sahel from Senegal until Sudan is dominated by positive cumNDVI and rainfall trends. These result from drought recovery, although land cover change in the form of agricultural expansion can be an additional driver (Brink and Eva 2009; Tottrup and Rasmussen 2004).

\section{References}

Ahuja V (1998) Land degradation, agricultural productivity and common property: evidence from Côte d'Ivoire. Environ Dev Econ 3(1):7-34

Akiwumi FA, Butler DR (2008) Mining and environmental change in Sierra Leone, West Africa: a remote sensing and hydrogeomorphological study. Environ Monit Assess 142(1-3):309-318

Alexandratos N (1999) World food and agriculture: outlook for the medium and longer term. Proc Natl Acad Sci US Am 96(11):5908-5914

Anyamba A, Tucker CJ (2005) Analysis of Sahelian vegetation dynamics using NOAA-AVHRR NDVI data from 1981-2003. J Arid Environ 63(3):596-614

Awaya Y, Kodani E, Tanaka K, Liu J, Zhuang D, Meng Y (2004) Estimation of the global net primary productivity using NOAA images and meteorological data: changes between 1988 and 1993. Int J Remote Sens 25(9):1597-1613

Barrios S, Ouattara B, Strobl E (2008) The impact of climatic change on agricultural production: is it different for Africa? Food Policy 33(4):287-298

Bartholomé E, Belward AS (2005) GLC2000: a new approach to global land cover mapping from earth observation data. Int J Remote Sens 26(9):1959-1977

Battisti DS, Naylor RL (2009) Historical warnings of future food insecurity with unprecedented seasonal heat. Science 323(5911):240-244

de Beurs KM, Henebry GM (2005a) Land surface phenology and temperature variation in the International Geosphere-Biosphere Program high-latitude transects. Glob Chang Biol 11(5):779-790

de Beurs KM, Henebry GM (2005b) A statistical framework for the analysis of long image time series. Int J Remote Sens 26(8):1551-1573

Bewket W (2002) Land cover dynamics since the 1950s in Chemoga watershed, Blue Nile basin, Ethiopia. Mt Res Dev 22(3):263-269

Bicheron P, Defourny P, Brockmann C, Schouten L, Vancutsem C, Huc M, Bontemps S, Leroy M, Achard F, Herold M, Ranera F, Arino O (2008) Globcover: products description and validation report. Tech. rep., Medias France

Biradar CM, Thenkabail PS, Noojipady P, Li YJ, Dheeravath V, Turral H, Velpuri M, Gumma MK, Gangalakunta ORP, Cai XL, Xiao XM, Schull MA, Alankara RD, Gunasinghe S, Mohideen S (2009) A global map of rainfed cropland areas (GMRCA) at the end of last millennium using remote sensing. International Journal of Applied Earth Observation and Geoinformation 11(2):114-129

Bounoua L, DeFries R, Collatz GJ, Sellers P, Khan H (2002) Effects of land cover conversion on surface climate. Climatic Change 52(1-2):29-64

Brink AB, Eva HD (2009) Monitoring 25 years of land cover change dynamics in Africa: a sample based remote sensing approach. Appl Geogr 29(4):501-512

Brown ME (2008) Famine early warning systems and remote sensing data. Springer Verlag, Berlin Heidelberg, Germany

Brown ME, de Beurs KM (2008) Evaluation of multi-sensor semi-arid crop season parameters based on NDVI and rainfall. Remote Sens Environ 112(5):2261-2271

Brown ME, Funk CC (2008) Food security under climate change. Science 319(5863):580-581

Brown ME, Lary DJ, Vrieling A, Stathakis D, Mussa H (2008) Neural networks as a tool for constructing continuous NDVI time series from AVHRR and MODIS. Int J Remote Sens 29(24):7141-7158 
Brown ME, de Beurs KM, Vrieling A (2010) The response of African land surface phenology to large scale climate oscillations. Remote Sens Environ 114(10):2286-2296

Camberlin P, Moron V, Okoola R, Philippon N, Gitau W (2009) Components of rainy seasons' variability in Equatorial East Africa: onset, cessation, rainfall frequency and intensity. Theor Appl Climatol 98(3-4):237-249

Cao M, Prince SD, Small J, Goetz SJ (2004) Remotely sensed interannual variations and trends in terrestrial net primary productivity 1981-2000. Ecosystems 7(3):233-242

Chen J, Jönsson P, Tamura M, Gu Z, Matsushita B, Eklundh L (2004) A simple method for reconstructing a high-quality NDVI time-series data set based on the Savitzky-Golay filter. Remote Sens Environ 91(3-4):332-344

Cheung WH, Senay GB, Singh A (2008) Trends and spatial distribution of annual and seasonal rainfall in Ethiopia. Int J Climatol 28(13):1723-1734

Cooper PJM, Dimes J, Rao KPC, Shapiro B, Shiferaw B, Twomlow S (2008) Coping better with current climatic variability in the rain-fed farming systems of sub-Saharan Africa: an essential first step in adapting to future climate change? Agric Ecosyst Environ 126(1-2):24-35

Dai A, Lamb PJ, Trenberth KE, Hulme M, Jones PD, Xie P (2004) The recent Sahel drought is real. Int J Climatol 24(11):1323-1331

Dilley M (2000) Reducing vulnerability to climate variability in southern Africa: the growing role of climate information. Climatic Change 45(1):63-73

Dixon J, Gulliver A, Gibbon D (2001) Farming systems and poverty: improving farmers' livelihoods in a changing world. FAO, Rome and World Bank, Washington DC

Enfors EI, Gordon LJ (2007) Analysing resilience in dryland agro-ecosystems: a case study of the Makanya catchment in Tanzania over the past 50 years. Land Degrad Dev 18(6):680-696

Fermont AM, van Asten PJA, Giller KE (2008) Increasing land pressure in East Africa: the changing role of cassava and consequences for sustainability of farming systems. Agric Ecosyst Environ 128(4):239-250

Friedl MA, McIver DK, Hodges JCF, Zhang XY, Muchoney D, Strahler AH, Woodcock CE, Gopal S, Schneider A, Cooper A, Baccini A, Gao F, Schaaf C (2002) Global land cover mapping from MODIS: algorithms and early results. Remote Sens Environ 83(1-2):287-302

Fritz S, See L (2008) Identifying and quantifying uncertainty and spatial disagreement in the comparison of Global Land Cover for different applications. Glob Chang Biol 14(5):1057-1075

Fuller DO (1998) Trends in NDVI time series and their relation to rangeland and crop production in Senegal, 1987-1993. Int J Remote Sens 19(10):2013-2018

Funk C, Budde ME (2009) Phenologically-tuned MODIS NDVI-based production anomaly estimates for Zimbabwe. Remote Sens Environ 113(1):115-125

Gasana J (2002) Remember Rwanda? World Watch 15(5):24-33

Giannini A, Saravanan R, Chang P (2003) Oceanic forcing of Sahel rainfall on interannual to interdecadal time scales. Science 302(5647):1027-1030

Giannini A, Biasutti M, Held IM, Sobel AH (2008) A global perspective on African climate. Climatic Change 90(4):359-383

Glantz MH, Gommes R, Ramasamy S (2009) Coping with a changing climate: considerations for adaptation and mitigation in agriculture. FAO, Rome, Italy

Goetz SJ, Prince SD, Small J, Gleason ACR (2000) Interannual variability of global terrestrial primary production: results of a model driven with satellite observations. J Geophys Res 105(D15):20,077-20,091

Graef F, Haigis J (2001) Spatial and temporal rainfall variability in the Sahel and its effects on farmers' management strategies. J Arid Environ 48(2):221-231

Gregory PJ, Ingram JSI, Brklacich M (2005) Climate change and food security. Philos Trans R Soc, B Biol Sci 360(1463):2139-2148

Harper GJ, Steininger MK, Tucker CJ, Juhn D, Hawkins F (2007) Fifty years of deforestation and forest fragmentation in Madagascar. Environ Conserv 34(4):325-333

Helldén U, Tottrup C (2008) Regional desertification: a global synthesis. Glob Planet Change 64(3-4):169-176

Herrmann SM, Anyamba A, Tucker CJ (2005) Recent trends in vegetation dynamics in the African Sahel and their relationship to climate. Glob Environ Change 15(4):394-404

Heumann BW, Seaquist JW, Eklundh L, Jönsson P (2007) AVHRR derived phenological change in the sahel and soudan, africa, 1982-2005. Remote Sens Environ 108(4):385-392

Hickler T, Eklundh L, Seaquist JW, Smith B, Ardö J, Olsson L, Sykes MT, Sjöström M (2005) Precipitation controls Sahel greening trend. Geophys Res Lett 32(21):1-4 
Huete A, Didan K, Miura T, Rodriguez EP, Gao X, Ferreira LG (2002) Overview of the radiometric and biophysical performance of the MODIS vegetation indices. Remote Sens Environ 83(1-2):195-213

Ifejika Speranza C, Kiteme B, Wiesmann U (2008) Droughts and famines: the underlying factors and the causal links among agro-pastoral households in semi-arid Makueni district, Kenya. Glob Environ Change 18(1):220-233

Imhoff ML, Bounoua L, Ricketts T, Loucks C, Harriss R, Lawrence WT (2004) Global patterns in human consumption of net primary production. Nature 429(6994):870-873

IPCC (2007) Climate change 2007: impacts, adaptation and vulnerability. Contribution of Working Group II to the Fourth Assessment Report of the Intergovernmental Panel on Climate Change. Cambridge University Press, Cambridge, UK

Justice CO, Townshend JRG, Holben BN, Tucker CJ (1985) Analysis of the phenology of global vegetation using meteorological satellite data. Int J Remote Sens 6(8):1271-1318

Kabanda TA, Jury MR (1999) Inter-annual variability of short rains over northern Tanzania. Clim Res 13(3):231-241

Kurukulasuriya P, Mendelsohn R, Hassan R, Benhin J, Deressa T, Diop M, Eid HM, Fosu KY, Gbetibouo G, Jain S, Mahamadou A, Mano R, Kabubo-Mariara J, El-Marsafawy S, Molua E, Ouda S, Ouedraogo M, Séne I, Maddison D, Seo SN, Dinar A (2006) Will African agriculture survive climate change? World Bank Econ Rev 20(3):367-388

Lal R (2007) Anthropogenic influences on world soils and implications to global food security. Adv Agron 93:69-93

Laux P, Kunstmann H, Bardossy A (2008) Predicting the regional onset of the rainy season in West Africa. Int J Climatol 28(3):329-342

Lewis LA, Nyamulinda V (1996) The critical role of human activities in land degradation in Rwanda. Land Degrad Dev 7(1):47-55

Liu J, Fritz S, van Wesenbeeck CFA, Fuchs M, You L, Obersteiner M, Yang H (2008) A spatially explicit assessment of current and future hotspots of hunger in Sub-Saharan Africa in the context of global change. Glob Planet Change 64(3-4):222-235

Lo Seen Chong D, Mougin E, Gastellu-Etchegorry JP (1993) Relating the global vegetation index to net primary productivity and actual evapotranspiration over Africa. Int J Remote Sens 14(8):1517-1546

Lobell DB, Burke MB, Tebaldi C, Mastrandrea MD, Falcon WP, Naylor RL (2008) Prioritizing climate change adaptation needs for food security in 2030. Science 319(5863):607-610

Malley ZJU, Taeb M, Matsumoto T (2009) Agricultural productivity and environmental insecurity in the Usangu plain, Tanzania: policy implications for sustainability of agriculture. Environment, Development and Sustainability 11(1):175-195

Maxwell DG (1996) Measuring food insecurity: The frequency and severity of "coping strategies". Food Policy 21(3):291-303

McConnell WJ, Sweeney SP, Mulley B (2004) Physical and social access to land: spatio-temporal patterns of agricultural expansion in Madagascar. Agric Ecosyst Environ 101(2-3):171-184

Milesi C, Hashimoto H, Running SW, Nemani RR (2005) Climate variability, vegetation productivity and people at risk. Glob Planet Change 47(2-4 SPEC. ISS.):221-231

Minten B, Barrett CB (2008) Agricultural technology, productivity, and poverty in Madagascar. World Dev 36(5):797-822

Mishra A, Hansen JW, Dingkuhn M, Baron C, Traoré SB, Ndiaye O, Ward MN (2008) Sorghum yield prediction from seasonal rainfall forecasts in Burkina Faso. Agric For Meteorol 148(11):17981814

Misselhorn AA (2005) What drives food insecurity in southern Africa? A meta-analysis of household economy studies. Glob Environ Change 15(1):33-43

Mitchell TD, Jones PD (2005) An improved method of constructing a database of monthly climate observations and associated high-resolution grids. Int J Climatol 25(6):693-712

Nemani RR, Keeling CD, Hashimoto H, Jolly WM, Piper SC, Tucker CJ, Myneni RB, Running SW (2003) Climate-driven increases in global terrestrial net primary production from 1982 to 1999. Science 300(5625):1560-1563

Nicholson SE (1993) An overview of African rainfall fluctuations of the last decade. J Climate 6(7):1463-1466

Nicholson SE, Davenport ML, Malo AR (1990) A comparison of the vegetation response to rainfall in the Sahel and East Africa, using normalized difference vegetation index from NOAA AVHRR. Climatic Change 17(2-3):209-241 
Olsson L, Eklundh L, Ardo J (2005) A recent greening of the Sahel—trends, patterns and potential causes. J Arid Environ 63(3):556-566

Parry M, Rosenzweig C, Livermore M (2005) Climate change, global food supply and risk of hunger. Philos Trans R Soc B: Biol Sci 360(1463):2125-2138

Philippon N, Jarlan L, Martiny N, Camberlin P, Mougin E (2007) Characterization of the interannual and intraseasonal variability of West African vegetation between 1982 and 2002 by means of NOAA AVHRR NDVI data. J Climate 20(7):1202-1218

Pinzón JE, Brown ME, Tucker CJ (2005) Satellite time series correction of orbital drift artifacts using empirical mode decomposition. In: Huang N, Shen SSP (eds) Hilbert-Huang transform: introduction and applications, World Scientific, Hackensack NJ, pp 167-186

Ramankutty N, Evan AT, Monfreda C, Foley JA (2008) Farming the planet: 1. Geographic distribution of global agricultural lands in the year 2000. Glob Biogeochem Cycles 22(1):GB1003

Reason CJC, Landman W, Tennant W (2006) Seasonal to decadal prediction of southern African climate and its links with variability of the Atlantic Ocean. Bull Am Meteorol Soc 87(7):941-955

Reed BC, Brown JF, Vanderzee D, Loveland TR, Merchant JW, Ohlen DO (1994) Measuring phenological variability from satellite imagery. J Veg Sci 5(5):703-714

Reed BC, Schwartz MD, Xiao X (2009) Remote sensing phenology: status and the way forward. In: Noormets A (ed) Phenology of ecosystem processes: applications in global change research, Springer-Verlag, New York, pp 231-246

Ringler C, Bryan E, Biswas A, Cline SA (2010) Water and food security under global change. In: Ringler C, Biswas AK, Cline SA (eds) Global change: impacts on water and food security, Springer-Verlag, Berlin Heidelberg, pp 3-15

Roerink GJ, Menenti M, Verhoef W (2000) Reconstructing cloudfree NDVI composites using Fourier analysis of time series. Int J Remote Sens 21(9):1911-1917

Rojas O (2007) Operational maize yield model development and validation based on remote sensing and agro-meteorological data in Kenya. Int J Remote Sens 28(17):3775-3793

Rojas O (2009) Crop monitoring in Kenya - August 2009 - MARS Bulletin. Tech. rep., Joint Research Centre of the European Commission

Rojas O, Rembold F, Royer A, Negre T (2005) Real-time agrometeorological crop yield monitoring in Eastern Africa. Agronomie 25(1):63-77

Running SW, Nemani RR, Heinsch FA, Zhao M, Reeves M, Hashimoto H (2004) A continuous satellite-derived measure of global terrestrial primary production. BioScience 54(6):547-560

Rutunga V, Janssen BH, Mantel S, Janssens M (2007) Soil use and management strategy for raising food and cash output in Rwanda. J Food Agric Environ 5(3-4):434-441

Savitzky A, Golay MJE (1964) Smoothing and differentiation of data by simplified least squares procedures. Anal Chem 36(8):1627-1639

Schreck III CJ, Semazzi FHM (2004) Variability of the recent climate of eastern Africa. Int J Climatol 24(6):681-701

Skarstein R (2005) Economic liberalization and smallholder productivity in Tanzania. from promised success to real failure, 1985-1998. Journal of Agrarian Change 5(3):334-362

Slegers MFW (2008) "If only it would rain": Farmers' perceptions of rainfall and drought in semi-arid central Tanzania. J Arid Environ 72(11):2106-2123

Smaling EMA, Dixon J (2006) Adding a soil fertility dimension to the global farming systems approach, with cases from africa. Agric Ecosyst Environ 116(1-2):15-26

Spearman C (1904) The proof and measurement of association between two things. Am J Psychol 15:72-101

Tadross MA, Hewitson BC, Usman MT (2005) The interannual variability on the onset of the maize growing season over South Africa and Zimbabwe. J Clim 18(16):3356-3372

Tateishi R, Ebata M (2004) Analysis of phenological change patterns using 1982-2000 Advanced Very High Resolution Radiometer (AVHRR) data. Int J Remote Sens 25(12):2287-2300

Teuling AJ, Stöckli R, Seneviratne SI (2010) Bivariate colour maps for visualizing climate data. Int J Climatol. doi:10.1002/joc.2153

Thornton PK, Jones PG, Alagarswamy G, Andresen J (2009) Spatial variation of crop yield response to climate change in East Africa. Glob Environ Change 19(1):54-65

Tottrup C, Rasmussen MS (2004) Mapping long-term changes in savannah crop productivity in Senegal through trend analysis of time series of remote sensing data. Agric Ecosyst Environ 103(3):545-560

Tucker CJ (1979) Red and photographic infrared linear combinations for monitoring vegetation. Remote Sens Environ 8(2):127-150 
Tucker CJ, Pinzón JE, Brown ME, Slayback DA, Pak EW, Mahoney R, Vermote EF, El Saleous N (2005) An extended AVHRR 8-km NDVI dataset compatible with MODIS and SPOT vegetation NDVI data. Int J Remote Sens 26(20):4485-4498

Vrieling A, De Beurs KM, Brown ME (2008) Recent trends in agricultural production of Africa based on AVHRR NDVI time series. In: Proceedings of SPIE - The International Society for Optical Engineering, vol 7104: 71040R

Wessels KJ, Prince SD, Malherbe J, Small J, Frost PE, VanZyl D (2007) Can human-induced land degradation be distinguished from the effects of rainfall variability? A case study in South Africa. J Arid Environ 68(2):271-297

White MA, Thornton PE, Running SW (1997) A continental phenology model for monitoring vegetation responses to interannual climatic variability. Glob Biogeochem Cycles 11(2):217-234

White MA, de Beurs KM, Didan K, Inouye DW, Richardson AD, Jensen OP, O'Keefe J, Zhang G, Nemani RR, van Leeuwen WJD, Brown JF, de Wit A, Schaepman M, Lin XM, Dettinger M, Bailey AS, Kimball J, Schwartz MD, Baldocchi DD, Lee JT, Lauenroth WK (2009) Intercomparison, interpretation, and assessment of spring phenology in North America estimated from remote sensing for 1982-2006. Glob Change Biol 15(10):2335-2359

Zhang X, Friedl MA, Schaaf CB, Strahler AH, Liu Z (2005) Monitoring the response of vegetation phenology to precipitation in Africa by coupling MODIS and TRMM instruments. J Geophys Res 110:D12103 